\title{
The prevalence of hypertension and the relationship with body composition in Grade 1 learners in the North West Province of South Africa
}

\author{
Chanelle Kemp ${ }^{1}$ (MSc) \\ Anita E Pienaar ${ }^{1}$ (PhD) \\ Aletta E Schutte ${ }^{2}$ (PhD) \\ ${ }^{1}$ School for Biokinetics, Recreation and Sports Science in the Nicharea Phasrec \\ ${ }^{2}$ Hypertension in Africa Research Team (HART) \\ North-West University (Potchefstroom Campus), Potchefstroom, South Africa \\ Correspondence to: AE Pienaar (Anita.Pienaar@nwu.ac.za)
}

\begin{abstract}
Objective. To determine the prevalence of hypertension in Grade 1 learners in the North West Province of South Africa and to investigate the association between blood pressure (BP) and body composition of these children.

Methods. Data were collected by means of a stratified random sampling procedure from 816 Grade 1 learners (419 boys, 397 girls) with a mean age of $6.78 \pm 0.49$ years (mean $\pm S D$ ), in the NWCHILD-study. Height, weight, skinfolds (subscapular, triceps, calf) and waist circumference were measured. The international recommended cut-off values of Cole et al. (2000) for body mass index (BMI) were used. Hypertension, defined as the average of two separate $B P(B P)$ readings, where the systolic BP and diastolic BP is $>95$ th percentile for age, sex and height, was determined by means of an Omron 705CP-II.

Results. The overall prevalence of prehypertension and hypertension was $8.5 \%$ and $24.9 \%$, respectively. Both systolic and diastolic BP was positively associated with BMI, body fat percentage and waist circumference. Boys and girls showed a similar prevalence of hypertension. A higher percentage of black children were hypertensive compared with whites, although the difference in BP of the groups was not significant. A high percentage of children with normal weight also showed increased levels of BP. Conclusions. High prevalences of hypertension were found in Grade 1 learners in the North West Province of South Africa. Small practical significant associations existed between BP and body composition. BP screening is therefore considered important in the paediatric population. Interventions which include physical activity are recommended to reduce potential cardiovascular complications and obesity among children. Other contributing factors to high BP amongst young children should also be investigated.
\end{abstract}

\section{Introduction}

High blood pressure (hypertension) is the greatest risk factor for cardiovascular disease, ${ }^{1}$ which is responsible for up to 7 million deaths worldwide every year. ${ }^{2}$ The Centres for Disease Control and Prevention (CDC) indicates that 1 in 3 adults in America have hypertension ${ }^{3}$ and the same trend is found in South Africa, where $55 \%$ of adults 30 years and older have hypertension. ${ }^{4}$
Until recently, hypertension was a rare phenomenon amongst children, possibly due to fewer environmental stressors, higher physical activity levels, a lower prevalence of obesity and a healthier lifestyle. ${ }^{5}$ Chiolero et al. ${ }^{6}$ are of the opinion that the worldwide increase in obesity amongst children over the last two decades probably resulted in an increase in the incidence of hypertension in children. ${ }^{6}$ In this respect, Munter et al. ${ }^{7}$ found that the systolic and diastolic BP of children were respectively $1.4 \mathrm{mmHg}$ and $3.3 \mathrm{mmHg}$ higher in 1999 - 2000 than in 1988 - 1994 and attribute this increase in hypertension largely to the increased incidence of overweight children. Whitney and Rolfes ${ }^{8}$ report that obesity contributes to the development of hypertension because additional adipose tissue contains extra capillaries through which the blood has to pump and, consequently, puts extra strain on the heart and veins, which results in increased BP. A South African study on 5 -year-old children indicated that $11.6 \%$ of these children suffered from hypertension, ${ }^{9}$ while the study of Monyeki et al. ${ }^{10}$ conducted on $6-13$-year-old children from rural communities revealed that $1.0-5.8 \%$ of the boys and $3.1-11.4 \%$ of the girls had hypertension. In this study there was a direct association between the prevalence of hypertension amongst the children from rural communities and an increased body mass index (BMI). ${ }^{10}$

Research evidence indicates that even a moderate increase in BP could have a negative effect on the vascular structure and function of children. ${ }^{11}$ Children with increased BP could develop target organ damage and retinal abnormalities. ${ }^{12}$ Furthermore, such children are also more at risk of hypertension-related illnesses in their adult lives. 13

Overweight and obesity have increased drastically in children over the last 2 decades. ${ }^{14}$ The phenomenon has occurred throughout the world, including in South Africa, and is regarded as a serious health problem as it could have an effect on current and future public health. ${ }^{15}$ Statistics in South Africa indicate that in children between the ages of 6 and 13 years, $14.0 \%$ and $3.2 \%$ of boys are overweight and obese respectively, compared to $17.9 \%$ and $4.9 \%$ of girls (overweight and obese). ${ }^{16}$

Sorof et al. ${ }^{17}$ further report that hypertension occurs in $33 \%$ of children who are obese compared with $11 \%$ in those children who are not obese. Various studies also show that overweight children display higher systolic BP than children of normal weight. ${ }^{5,18}$ A study 
of 6 - 13-year-old South African children indicated that there is a positive correlation between the BMI and BP of the children, even after adjustments have been made for age, gender and height. ${ }^{19}$ The results of this study, however, are only based on children from disadvantaged communities.

Research indicates an increase in child obesity in South Africa and this could possibly contribute to an increased prevalence of hypertension amongst children in South Africa. ${ }^{20}$ Because of the potential health risks of hypertension, action needs to be taken to address this incidence. However, to develop adequate preventive strategies, it is important to determine the relationship between BP and body composition in South African children. In particular there is a gap in the literature with regard to this relationship within the diverse population of South Africa, and especially the young child population. Only a few studies could be found that examined the relationship of hypertension with overweight in South African child populations, ${ }^{10,19}$ and the studies were mainly relevant to children of disadvantaged communities. Hence, the aim of this study was to determine the prevalence of hypertension in Grade 1 learners and, more specifically, to determine the relationship between the BP and body composition of Grade 1 learners in the North West Province.

\section{Methods}

\section{Research group}

The research formed part of the NW-CHILD (Child-Health-Integrated-Learning and Development) study. Grade 1 learners in the North West Province of South Africa served as the target population for the study. The total number of participants identified for the study was 880 Grade 1 learners. The research group was selected by means of a stratified random sample in conjunction with the Statistical Consultation Service of the North West University. To determine the research group, a list of names of schools in the North West Province was obtained from the Department of Education. From the list of schools in the North West Province, which are grouped in 4 education districts, each representing 12 - 22 regions with approximately 20 schools (minimum 12, maximum 47) per region, regions and schools were randomly selected with regard to population density and school status (quintile 1, i.e. schools from poor economic sectors to quintile 5 , i.e. schools from good economic sectors). Boys and girls in Grade 1 were then randomly selected from each school. Twenty schools, from 4 districts with a minimum of 40 children per school and with an even gender distribution, were involved in the study. The total group that was measured consisted of 816 learners ( 419 boys and 397 girls) with an average age of 6.78 years and an ethnic distribution of 567 black, 218 white, 20 coloured and 11 Indian learners. Thirteen parents $(1.5 \%)$ did not consent to participation, while the rest of the selected participants were absent at school on the day of testing or had to be excluded because of incorrect ages that were provided by the schools.

The principals of the various identified schools were asked for permission to collect the data during school hours. If the numbers of learners in the school allowed it, 60 Grade 1 learners were randomly selected and received informed consent forms that had to be completed by their parents. This was done to ensure that informed consent would be granted by the parents of a minimum of 40 learners who needed to be measured at each school. The learners whose parents reacted positively to the above-mentioned forms, underwent the tests.
Ethical approval for the execution of the study was obtained from the Ethics Committee of the NWU (No. NW 0007009 S1). Permission was also obtained from the Education Department of the North West Province.

\section{Anthropometric measurements}

The anthropometric measurements included the following: height $(\mathrm{cm})$, body mass $(\mathrm{kg}), 3$ skinfolds (subscapular, triceps and medial calf) $(\mathrm{mm})$ and waist circumference $(\mathrm{cm})$. These variables measured were measured by trained postgraduate students in Kinderkinetics in accordance with the protocol of the International Society for the Advancement of Kinantropometry. ${ }^{21}$ Height was measured barefoot to the nearest $0.1 \mathrm{~cm}$ by means of a portable stadiometer, and body mass was measured with an electronic scale (BF 511, Omron) to the nearest $0.1 \mathrm{~kg}$. From the height and body mass measurement the body mass index (BMI) was calculated for each participant. Skinfolds were measured with a pair of Harpenden skinfold callipers and each skinfold was measured twice to obtain the average of the two measurements. These skinfold measurements were selected because, according to Meredith and Welk, ${ }^{22}$ they show the highest correlation with the overall percentage of fat in the bodies of children. Because the BMI of children changes continually as they get older, Cole and co-workers ${ }^{23}$ determined age-specific BMI cut-off values to identify obesity in growing children and these were used to categorise the participants into a normal weight, overweight or obese group. The cut-off values for 6-year-old overweight and obese children are $>17.34 \mathrm{~kg} / \mathrm{m}^{2}$ and $>19.65 \mathrm{~kg} / \mathrm{m}^{2}$, while for 7 -year-old children they are $>17.75 \mathrm{~kg} / \mathrm{m}^{2}$ and $>20.51 \mathrm{~kg} / \mathrm{m}^{2}$, respectively. ${ }^{23}$ Waist circumference, which was measured at the narrowest point between the lower costal (10th rib) border and the crista iliaca, was measured in the standing position with a standard measuring tape $(0.1 \mathrm{~mm}$ intervals).

\section{Blood pressure}

BP was measured with an Omron 705CP-II, (Kyoto, Japan). The width of the cuff (small $17-22 \mathrm{~cm}$, medium $22-32 \mathrm{~cm}$, large $32-42$ $\mathrm{cm}$ ) was adapted to the arm width. BP was measured while the child was seated, with the left arm resting on a table top with the palm turned upwards. Duplicate readings were recorded after the child had rested for 5 minutes. The mean of the two readings was used to determine the BP. Normal BP is defined as systolic and/or diastolic $\mathrm{BP}$ less than the 90th percentile for age, gender and height according to the cut-off values of the National High BP Education Program Working Group (NHBPEP) on high BP in children and adolescents; ${ }^{24}$ prehypertension is defined as systolic and/or diastolic BP greater than or equal to the 90th percentile, but less than the 95th percentile and paediatric hypertension is defined as systolic and/or diastolic BP greater than or equal to the 95th BP percentile for age, gender and height. ${ }^{24}$

\section{Statistical analyses}

Statistica ${ }^{25}$ was used to analyse the data. A proportionally stratified sample was drawn with regard to ethnicity by making use of the population constitution data from Statistics South Africa ${ }^{26}$ to ensure that the data could be generalised to children in the North West Province. For the purpose of description, data were analysed on the basis of means, maximum and minimum values and standard deviations (sd). Data were also further analysed by making use of Spearman correlation coefficients to analyse the relationship between BP and body composition. For the interpretation of practical significance, the following guidelines of Cohen ${ }^{27}$ concerning magnitude of effect were used, namely, $d>0.1$ indicates a small effect; $d>0.3$ indicates a moderate effect and $d>0.5$ indicates a large effect. In addition, use 
Table I. Number and percentage of Grade 1 learners according to classification in BMI-groups

\begin{tabular}{|c|c|c|c|c|c|c|c|}
\hline & \multicolumn{2}{|c|}{ Normal weight } & \multicolumn{2}{|c|}{ Overweight } & \multicolumn{2}{|c|}{ Obese } & \multirow{2}{*}{$\begin{array}{c}\text { Total } \\
\text { (N) }\end{array}$} \\
\hline & (n) & $(\%)$ & (n) & $(\%)$ & (n) & $(\%)$ & \\
\hline Group & 721 & 88.4 & 64 & 7.8 & 31 & 3.8 & 816 \\
\hline Boys & 378 & 90.2 & 27 & 6.4 & 14 & 3.3 & 419 \\
\hline Girls & 343 & 86.4 & 37 & 9.3 & 17 & 4.3 & 397 \\
\hline White & 175 & 80.3 & 29 & 13.3 & 14 & 6.4 & 218 \\
\hline Black & 517 & 91.2 & 34 & 6.0 & 16 & 2.8 & 567 \\
\hline
\end{tabular}

Table II. Prevalence of prehypertension and hypertension amongst Grade 1 learners according to BMI categories

\begin{tabular}{|c|c|c|c|c|c|c|c|c|c|}
\hline & \multicolumn{2}{|c|}{$\begin{array}{l}\text { Normal weight } \\
\qquad(n=721)\end{array}$} & \multicolumn{2}{|c|}{$\begin{array}{l}\text { Overweight } \\
\quad(n=64)\end{array}$} & \multicolumn{2}{|c|}{$\begin{array}{l}\text { Obese } \\
(n=31)\end{array}$} & \multirow[t]{2}{*}{$p$ for trend } & \multicolumn{2}{|c|}{ Total } \\
\hline & (n) & $(\%)$ & (n) & $(\%)$ & (n) & $(\%)$ & & (n) & (\%) \\
\hline \multicolumn{10}{|l|}{ Prehypertension } \\
\hline Boys & 34 & 9.0 & 4 & 14.8 & 3 & 21.4 & 0.15 & 41 & 9.8 \\
\hline Girls & 22 & 6.4 & 3 & 8.1 & 3 & 17.7 & 0.02 & 28 & 6.8 \\
\hline White & 12 & 5.5 & 3 & 1.4 & 4 & 1.8 & 0.08 & 19 & 8.7 \\
\hline Black & 41 & 7.2 & 4 & 0.7 & 2 & 0.4 & 0.05 & 47 & 8.3 \\
\hline Total group & 56 & 7.8 & 7 & 10.9 & 6 & 19.4 & 0.008 & 69 & 8.5 \\
\hline \multicolumn{10}{|l|}{ Hypertension } \\
\hline Boys & 96 & 25.4 & 3 & 11.1 & 5 & 35.7 & 0.07 & 104 & 24.8 \\
\hline Girls & 82 & 23.9 & 11 & 29.7 & 6 & 35.3 & 0.14 & 99 & 24.9 \\
\hline White & 40 & 18.3 & 4 & 1.8 & 3 & 1.4 & 0.004 & 47 & 21.6 \\
\hline Black & 130 & 22.9 & 10 & 1.8 & 7 & 1.2 & 0.47 & 147 & 25.9 \\
\hline Total group & 178 & 24.7 & 14 & 21.9 & 11 & 35.5 & 0.028 & 203 & 24.9 \\
\hline
\end{tabular}

was made of a one-way analysis of variance to determine significant differences between the groups (normal weight, overweight and obese), and logistic regression was used to determine trends with regards to prevalence of prehypertension and hypertension between the subgroups. Because of the small number of coloured and Indian children that entered the sample, these children were excluded from the analysis of race differences, although their data were considered in the other results.

\section{Results}

Table I displays the descriptive statistics of the research group. The table shows that $88.4 \%$ of the learners were in the normal weight category, $7.8 \%$ into the overweight category and $3.8 \%$ into the obese category. The table also shows that a smaller percentage of the boys in comparison with the girls were in the overweight $(6.4 \% \mathrm{com}$ pared with $9.3 \%$ ) and obese (3.3\% compared with $4.3 \%$ ) categories. A smaller percentage of the black learners in comparison with the white learners fell into the overweight $(6.0 \%$ compared with $13.3 \%)$ and obese $(2.8 \%$ compared with $6.4 \%)$ categories.

Table II displays the percentage of learners of the total group, and race and gender separately, that can be classified with prehypertension and hypertension in the various BMI groups. A greater percentage of the research group were in the hypertension group compared with the prehypertension group. It appears that the prevalence of prehypertension may increase with an increase in BMI. The obese group displayed the highest prevalence of hypertension in comparison with the normal and overweight groups. Boys showed a higher prevalence of prehypertension than the girls $(9.8 \%$ compared with $6.8 \%$ ), while the prevalence of hypertension in the boys and the girls was similar $(24.8 \%$ compared with $24.9 \%)$. The prevalence of prehypertension was similar (8.7\% compared with $8.3 \%)$, in the white and the black children, while black children displayed a higher prevalence of hypertension than the white children (25.9\% compared with $21.6 \%)$.

Correlation coefficients were used to determine the relationship of systolic and diastolic BP with body composition (BMI, body fat percentage and waist circumference) of the participants. All the correlations were statistically and practically significant. Systolic and diastolic BP had significant $(p<0.01)$ positive correlations with BMI $(r=0.22 ; r=0.18)$, body fat percentage $(r=0.17 ; r=0.16)$ and waist circumference $(r=0.21 ; r=0.19)$, although only with small practical significance ( $d$-value $>0.1$ ). These correlations were further analysed by means of covariance of analysis in Table III where the mean values for the systolic and diastolic BP of the participants were analysed in the group in the 3 different BMI groups and also separately for gender and race. A $t$-test was used to make comparisons between gender and races and significant differences in this regard. These results are shown in the table with a\#. 
Table III. Mean BP of Grade 1 learners according to BMI categories

\begin{tabular}{|c|c|c|c|c|c|c|c|c|c|c|}
\hline \multirow[t]{2}{*}{ Variables } & \multicolumn{3}{|c|}{ Normal weight (a) $(n=721)$} & \multicolumn{3}{|c|}{ Overweight (b) $(n=64)$} & \multicolumn{3}{|c|}{ Obese (c) $(n=31)$} & \multirow{2}{*}{$\begin{array}{l}P \text { for } \\
\text { trend }\end{array}$} \\
\hline & Mean & SD & $95 \% \mathrm{Cl}$ & Mean & SD & $95 \% \mathrm{Cl}$ & Mean & SD & $95 \% \mathrm{Cl}$ & \\
\hline \multicolumn{11}{|l|}{ Systolic BP (mmHg) } \\
\hline Total group $(n=816)$ & $96.8^{c}$ & 14.0 & $(13.6 ; 14.5)$ & $99.3^{c}$ & 11.1 & $(9.9 ; 12.6)$ & $106.1^{\mathrm{ab}}$ & 15.5 & $(13.2 ; 18.7)$ & $<0.001$ \\
\hline Boys $(n=419)$ & $98.0^{\mathrm{C}}$ & 14.4 & $(13.8 ; 15.1)$ & 99.7 & 7.7 & $(6.4 ; 9.7)$ & $105.6^{\mathrm{a}}$ & 17.6 & $(14.0 ; 23.5)$ & 0.012 \\
\hline Girls $(n=397)$ & $95.4^{\mathrm{bc \#}}$ & 13.5 & $(12.9 ; 14.2)$ & $99.1^{\mathrm{ac}}$ & 12.6 & $(10.9 ; 14.8)$ & $106.6 \mathrm{ab}$ & 13.5 & $(10.8 ; 17.8)$ & $<0.001$ \\
\hline White $(n=218)$ & 96.9 & 14.8 & $(13.4 ; 16.5)$ & 99.6 & 9.6 & $(7.6 ; 13.0)$ & 103.2 & 13.7 & $(9.9 ; 22.1)$ & 0.21 \\
\hline Black $(n=567)$ & $96.9^{c}$ & 14.0 & $(13.5 ; 14.5)$ & 99.4 & 11.7 & $(10.3 ; 13.6)$ & $106.1^{\mathrm{a}}$ & 15.8 & $(13.1 ; 19.8)$ & $<0.001$ \\
\hline \multicolumn{11}{|c|}{ Diastolic BP (mmHg) } \\
\hline Total group $(n=816)$ & $64.6^{\mathrm{c}}$ & 13.1 & $(12.7 ; 13.6)$ & $67.0^{\mathrm{c}}$ & 11.2 & $(10.0 ; 12.7)$ & $72.0^{\mathrm{ab}}$ & 14.8 & $(12.6 ; 17.9)$ & $<0.001$ \\
\hline Boys $(n=419)$ & $65.1^{c}$ & 13.6 & $(13.0 ; 14.2)$ & 65.2 & 10.0 & $(8.3 ; 12.5)$ & $71.2^{\mathrm{a}}$ & 15.0 & $(12.0 ; 20.0)$ & 0.047 \\
\hline Girls ( $n=397)$ & $64 .^{0 \mathrm{bc}}$ & 12.6 & $(12.1 ; 13.2)$ & $68.0^{\mathrm{a}}$ & 11.8 & $(10.2 ; 13.8)$ & $72.8^{\mathrm{a}}$ & 14.8 & $(11.9 ; 19.5)$ & $<0.001$ \\
\hline White $(n=218)$ & 63.9 & 12.6 & $(11.4 ; 14.1)$ & 63.7 & 7.6 & $(6.1 ; 10.3)$ & 69.3 & 14.0 & $(10.2 ; 22.6)$ & 0.28 \\
\hline Black $(n=567)$ & $64.6^{\mathrm{c}}$ & 13.2 & $(12.7 ; 13.7)$ & 68.2 & 12.1 & $(10.6 ; 14.0)$ & $72.8^{\mathrm{a}}$ & 15.3 & $(12.8 ; 19.2)$ & $<0.001$ \\
\hline
\end{tabular}

$\mathrm{BMI}=$ body mass index; $\mathrm{sd}=$ standard deviation; $\mathrm{a}=$ normal weight; $\mathrm{b}=$ overweight; $\mathrm{c}=$ obese; mean with superscript differed significantly on a $5 \%$ level; $\# \mathrm{p}$-value $<0.05$ gender and race differences; $\mathrm{Cl}=$ confidence interval.

Due to the small number of coloured and Indian children in the sample, these race groups were excluded from the analysis of race differences and only white and black children were compared. The systolic and diastolic mean BP values increased in the group as the $\mathrm{BMI}$ of the participants increased. The mean systolic and diastolic $\mathrm{BP}$ values of the normal weight and overweight children differed significantly from the obese children. Differences between the groups are indicated with superscripts $(a, b \& c)$. Boys in the normal weight group had significantly higher systolic BP values than the girls in this group. On the other hand, the girls in the obese group had higher systolic BP values in comparison with the boys in the obese group (not signifant) and the girls in the overweight and obese groups also had higher diastolic BP in comparison with the boys in the overweight and obese group (not significant). An analysis of possible race differences showed that there was a tendency for the diastolic BP values of black children to be higher than those of the white children in all 3 of the different BMI groups (not significant).

\section{Discussion}

The aim of this study was to determine the prevalence of hypertension in Grade 1 learners, as well as to determine the possible relationship between the BP and body composition of Grade 1 learners in the North West Province of South Africa.

Our results regarding prehypertension in the group of 6 - 7-yearolds indicate a prevalence of $8.5 \%$. This is similar to the findings of Hansen et al., ${ }^{28}$ who found a prevalence of $3.4 \%$ in a group of 3 - 18-year-old American children. With regards hypertension we showed a prevalence of $24.9 \%$, which is a slightly higher than the $22.3 \%$ indicated in a study conducted by Steyn et al. ${ }^{9}$ more than 10 years ago in South Africa. Research demonstrates that the prevalence of hypertension has increased over the last decade as a result of the increase in overweight and obesity amongst children. ${ }^{6}$ Monyeki et al., ${ }^{10}$ who focused on a relatively small group of black children $(n=203)$ from disadvantaged communities, reported a $3.9 \%$ prevalence of hypertension in 6 - 7-year-old children. However, none of the 6 - 7-year-old children fell into the overweight category, which could also possibly contribute to the lower prevalence of hypertension that was reported in the study. The $35.5 \%$ prevalence of hypertension that was found in the obese group of children coincides with a study by Sorof et al., ${ }^{17}$ who reported a $33.0 \%$ prevalence of hypertension in obese children (11.8 years old). However, South Africa lacks literature that reflects the prevalence of prehypertension and hypertension in 6 - 7-year-old children which could be used for comparison purposes.

The results further showed that systolic and diastolic BP had a significantly positive correlation with $\mathrm{BMI}$, body fat percentage and waist circumference, although the practical significance was small. These results concur with the study of Monyeki et al. ${ }^{10}$ on 6 - 13-year-old children in disadvantaged communities. Waist circumference showed a positive and significant correlation with systolic and diastolic BP and coincides with research by Cuestas et al. $^{29}$ on 2 - 9-year-old children. From the above-mentioned results it would appear that waist circumference could be used as a possible risk marker to identify children at risk of possible high BP.

The obese children had significantly higher systolic and diastolic BP compared with the normal weight and overweight children and an increase in BMI was consequently associated with an increase in BP. These results coincide with studies conducted on children that 
found the same trends. ${ }^{5,18}$ Morphological and functional changes that probably occurred in these children, such as arterial stiffness and left ventricular hypertrophy, ${ }^{30}$ carotid arterial wall thickening ${ }^{31}$ and early activation of vascular endothelium and platelets ${ }^{32}$ could be cited as possible reasons for this. All the changes associated with high BP that are reported in the literature indicate that the arteriosclerotic process already begins during the early childhood years.

However, the results also show that a large percentage $(24.7 \%$, $n=178)$ of the normal weight group $(n=721)$ was also classified with hypertension. The high prevalence of hypertension in this group indicates that other factors, excluding body composition, may also play a role in the increased prevalence of hypertension. Possible reasons that could be given for this include unhealthy dietary habits, such as a reduced intake of fruit and vegetables, a diet high in saturated fats and a high intake of salt. ${ }^{33}$ These unhealthy dietary habits of high intake of salt often occur in the South African population, seeing that bread is the staple food of large numbers of this population and it contains high levels of sodium chloride. Environmental stressors, such as violence and economic stressors, for example poverty, could possibly also have an influence on hypertension in children. ${ }^{5}$

Boys of the normal weight group had significantly higher systolic BP values than girls in the normal weight group. On the other hand, the girls in the obese group had higher systolic BP values compared with the boys in the obese group, although not statistically significant. Girls in the overweight and obese group also displayed higher mean diastolic BP values compared with boys in the overweight and obese group, although also not statistically significant. These results correspond with research by Agyemang et al. ${ }^{34}$ and Monyeki et al. ${ }^{10}$ which also found that girls had higher BP than boys. A possible reason could be that girls have a higher percentage of fat than boys, which contributes to a higher prevalence of overweight and obesity and, as a result, they display higher systolic and diastolic BP values.

As far as race differences are concerned, the mean diastolic BP values of the black children were higher than those of white children in all three of the different BMI groups, although not statistically significant. These results correspond with other research studies that also found that black children showed higher diastolic BP values than white children. $9,35,36$ These studies, however, did not analyse the different BMI groups separately. Furthermore, the results also show that the mean systolic BP of the black children was only higher than that of the white children in the obese group, although also not statistically significant. The studies of Dekkers et al. ${ }^{36}$ and Cruz et al. ${ }^{35}$ both show that the systolic BP of black children was higher than that of white children. The different BMI groups, however, were also not analysed separately in these studies. Possible reasons that can be given for this are differences in socio-economic status, genetic, endocrine and environmental factors, as well as cardiac function, diet and stress. ${ }^{37-39}$ Seedat ${ }^{37}$ further demonstrates that black hypertensive patients are more susceptible to cerebral bleeding and malignant hypertension, which is more inclined to give rise to congestive cardiac failure, while coronary cardiac diseases are less common. In contrast to this, coronary cardiac disease is the most important result of hypertension in the white community. These slight differences, although they can only be viewed as trends, could possibly indicate different causes of hypertension in the different race groups, and this speculation needs further research.

The prevalence of hypertension, as well as prehypertension that was found in this study of 7-year-old children is disturbing, especially when considering the associated health-related problems. A notable relationship was also found between the BP and body composition in the overall group of children, although this relationship could be mediated by high hypertensive percentages that were also found in the normal weight group.

BP during childhood is significantly associated with BP during adulthood. ${ }^{6}$ Therefore it is important to develop intervention programmes, especially those that are aimed at increasing levels of physical activity that would lead to weight loss in overweight and obese children and thus reduce the risk of hypertension. It is also advised that BP must be monitored from early childhood and that BP readings must be incorporated in the clinical evaluation of children on a routine basis so that possible cardiovascular risk factors can thus be monitored, especially in the case of overweight and obese children. This study, however, also shows that other factors besides body composition could have an effect on the prevalence of hypertension in children and follow-up studies are advised to obtain a better understanding of the influence of these factors. Among others, growth retardation is a possible factor that could have an effect on the increased prevalence of hypertension, especially amongst children of normal weight, as height is taken into consideration in BP percentile tables.

A shortcoming of the study was that, although two BP readings were taken five minutes apart, BP could only be taken once. However, most research studies conducted on children report this limitation. Although everything was also done to set the participants at ease with regard to the nature of the BP reading, a child could have been erroneously classified as hypertensive as a result of anxiety. This study is, however, the beginning of a longitudinal study during which follow-up data will be collected on BP status in 2013 and 2016 and baseline BP will consequently be monitored in this way. It has, moreover, also been reported that health workers often underdiagnose hypertension in children as the values for children are not as precise as those for adults, but have to be recorded from BP percentile tables and these tables are not always available in health care clinics. ${ }^{26}$ Gender differences were indicated, but could not be analysed thoroughly in the race groups due to the limited numbers of children in the different race groups. In spite of these shortcomings, the study brought valuable information to the fore regarding the current prevalence of hypertension amongst Grade 1 learners in the North West Province of South Africa and the effect of body composition, gender and race on the BP of these children.

\section{Conclusion}

High prevalences of hypertension were found in Grade 1 learners in the North West Province of South Africa. Small practical significant associations existed between BP and body composition. Screening for BP should therefore not be neglected in these children, especially within the black communities, where the prevalence of hypertension was higher than in the white children. We recommend that interventions, including physical activity, should be introduced to reduce potential cardiovascular complications and obesity among children. Other factors contributing to high BP amongst children should also be investigated.

\section{REFERENCES}

1. Vasan RS, Larson MG, Leip, et al. Impact of high-normal blood pressure on the risk of cardiovascular disease. N Engl J Med 2001;345(18):12911297.

2. Ezzati M, Lopez, AD, Rodgers A, Vanderhoorn S, Murray CJ. Comparative risk assessment collaborating group. Selected major risk factors and global and regional burden of disease. Lancet 2002;360:1347-1360. 
3. Centers for disease control and prevention (CDC). High BP 2010 www.cdc .gov/bloodpressure/facts_statistics.htm (accessed 6 May 2010).

4. Connor M, Rheeder P, Bryer A, et al. The South African stroke risk in general practice study. S Afr Med J 2005;95:334-339.

5. Lazarou X, Panagiotakos DB, Matalas AL. Lifestyle factors are determinants of children's blood pressure levels: the CYKIDS study. J Hum Hypertens 2009;23(7):456-463.

6. Chiolero A, Boyet P, Paradis G. Assessing secular trends in blood pressure in children and adolescents. J Hypertens 2009;23(6):426-427.

7. Munter $\mathrm{P}, \mathrm{He} \mathrm{J}$, Cutler JA, Wildman RP, Whelton PK. Trends in blood pressure among children and adolescents, 1999-2000. JAMA 2004;291:21072113.

8. Whitney EN, Rolfes SR. Understanding nutrition. 12th ed. London: Wadsworth, 2008.

9. Steyn L, De Wet T, Richter L, Cameron N, Levitt NS, Morrell C. Cardiovascular disease risk factors in five-year-old urban South African children - the Birth to Ten study. S Afr Med J 2000;90:719-726.

10. Monyeki KD, Kemper HCG, Makgae PJ. The association of fat patterning with blood pressure in rural South African children: the Ellisras Longitudinal Growth and Health Study. Int J Epidemiol 2006;35(1):114-120.

11. Barnes VA, Treiber FA, Davis H. Impact of transcendental meditation on cardiovascular function at rest and during acute stress in adolescents with high normal blood pressure. J Psychosom Res 2001;51:597-605.

12. Sorof JM, Turner J, Martin DS, et al. Cardiovascular risk factors and sequelae in hypertensive children identified by referral versus school-based screening. Hypertension 2004;43:214-218.

13. Chen $X$, Wang Y. Tracking of blood pressure from childhood to adulthood. A systematic review and meta-regression analysis. Circulation 2008;117:3171-3180

14. Ogden CL, Carroll MD, Curtin LR, Lamb MM, Flegal KM. Prevalence of high body mass index in US children and adolescents, 2007-2008. JAMA 2010;303(3)242-249.

15. Reilly JJ, Methven E, McDowell ZC, et al. Health consequences of obesity: systematic review. Arch Dis Child 2003;88(9):748-752.

16. Armstrong MEG, Lambert MI, Sharwood KA, Lambert EV. Obesity and overweight in South African primary school children - the Health of the Nation Study. S Afr Med J 2006;96(5):439-444.

17. Sorof JM, Poffenbarger T, Franco K, Bernard L, Portman RJ. Isolated systolic hypertension, obesity, and hyperkinetic hemodynamic states in children. J Pediatr 2002;140(6):660-666.

18. Flores-Huerta S, Klünder-Klünder M, Reyes De La Cruz L, Santos JI. Increase in body mass index and waist circumference is associated with high blood pressure in children and adolescents in Mexico City. Arch Med Res 2009;40:208-215

19. Makgae PJ, Monyeki KD, Brit SJ, Kemper HCG, Mashita J. Somatotype and blood pressure of rural South African children aged 6-13 years: Ellisras longitudinal growth and health study. Ann Hum Biol 2007;34(2):240251.

20. Armstrong, MEG, Lambert, MI, Lambert, EV. Secular trends in the prevalence of stunting, overweight and obesity among South African children (1994-2004). Eur J Clin Nutr 2011;65:835-840.
21. Marfell-Jones M, Olds T, Stewart A, Carter JEL. International standards for anthropometric assessment. ISAK: Potchefstroom, 2006.

22. Meredith MD, Welk GJ. Fitnessgram: Test administration manual: The Cooper institute for aerobics research. 2nd ed. Champaign IL: Human Kinetics Publishers, 2005

23. Cole TJ, Belizzi MC, Flegal KM, Dietz WH. Establishing a standard definition for child overweight and obesity worldwide: International survey. BMJ 2000;320:1240-1243

24. National high blood pressure education program working group $(\mathrm{NH}$ BPEP) on high blood pressure in children and adolescents. The fourth report on the diagnosis, evaluation and treatment of high BP in children and adolescents. Pediatrics 2004;114(Suppl. 2, 4th Report):555-576.

25. Statsoft. Statistica for Windows. Release 5.5: General conventions \& statistics. Tulsa, OK: StatSoft, 2010.

26. Statistics South Africa website www/statssa.gov.za/publicationstats.asp (accessed November 2009).

27. Cohen J. Statistical power analysis for the behavioural sciences. 2nd ed. Hillsdale, NJ: Erlbaum, 1988.

28. Hansen ML, Gunn PW, Kaelber DC. Underdiagnosis of hypertension in children and adolescents. JAMA 2007:298:874-879.

29. Cuestas E, Achaval A, Garces N, Larraya C. Waist circumference, dyslipidemia and hypertension in prepubertal children. Ann Pediatr 2007;67(1):44-50.

30. Mahmud A, Feely J. Adiponectin and arterial stiffness. Am J Hypertens 2005:18:1543-1548.

31. Iannuzzi A, Licenziati MR, Acampora C, et al. Carotid artery wall hypertrophy in children with metabolic syndrome. J Hum Hypertens 2008;22:83 88.

32. Meyer AA, Kundt G, Steiner M, Schuff-Werner P, Kienast W. Impaired flow-mediated vasodilation, carotid artery intima-media thickening, and elevated endothelial plasma markers in obese children: the impact of cardiovascular risk factors. Pediatrics 2006;117:1560-1567.

33. He FJ, Marrero NM, McGregor GA. Salt and blood pressure in children and adolescents. J Hum Hypertens 2008;22:4-11.

34. Agyemang C, Redekop WK, Owusu-Dabo E, Bruijnzeels MA. Blood pressure patterns in rural, semi-urban and urban children in the Ashanti region of Ghana, West Africa. BMC Public Health 2005;5:114-120.

35. Cruz ML, Huang TT, Johnson MS, Gower BA, Boran MI. Insulin sensitivity and blood pressure in black and white children. Hypertension 2002;40(1):18-22

36. Dekkers JC, Snieder H, Van Den Oord JCG, Treiber FA. Moderators of blood pressure development from childhood to adulthood: A 10-year longitudinal study. J Pediatr 2002;141(6):770-779.

37. Seedat YK. Hypertension in black South Africans. J Hum Hypertens 1999;13:97-103.

38. Ferreira I, Van Der Horst K, Wendel-Vos W, Kremers S, Van Lenthe FJ Brug J. Environmental correlates of physical activity in youth - a review and update. Obesity Rev 2007;8(2):129-154

39. Addo J, Leon DA. Socioeconomic position and hypertension: a study of urban civil servants in Ghana. J Epidemiol Community Health 2009;63(8):646-500. 